\title{
Analysis on the unit space design of primary and secondary school campus building teaching area
}

\author{
Jitao Tang ${ }^{1 . *}$,Yuan Zhang ${ }^{2}$ \\ ${ }^{1}$ Colledge of Civil Engineering,Nanjing Technology,Nanjing 210009,China \\ ${ }^{2}$ Facully of Architecture and Civil Engineer,Huaiyin Institute of Technology,Huaian 223001,China
}

\begin{abstract}
This paper takes the teaching area unit space of primary and secondary schools as the main research object, analyzes, discusses and studies the reasonable use size of teaching unit space, commonly used space combination mode and internal detail design of education space, analyzes the actual use of various space units, and discusses the advantages and disadvantages of different design methods. Finally, from the perspective of teachers and students, combined with the analysis of specific project cases, this paper puts forward the optimization design strategy of school teaching unit space in line with the use requirements and architectural aesthetics.
\end{abstract}

\section{Main idea of the article}

Campus building is an indispensable architectural form in the city. With the continuous increase of population in recent years and the opening of the two child policy, the construction scale of primary and secondary schools is also increasing. At the same time, the development of society and the renewal of education concept require the all-round development of students, which makes the architectural space of primary and secondary schools more and more abundant. As the main functional space of teaching area and the main place for students' study and teachers' office, more attention should be paid to the design of unit space in teaching area. Therefore, it is right and wrong to optimize the design of unit space in teaching area for the space design of the whole campus Often important. This paper mainly discusses the use area, combination mode and detail design of unit space in teaching area.

\section{Use area of unit space}

The teaching area can be divided into several types of unit space, including ordinary classroom, professional classroom, teacher's office and toilet. Among them, ordinary classroom and professional classroom are students' concentrated activity space, and teacher's office is teacher's activity space. The toilet is a service space.

\subsection{Ordinary classroom}

According to 5.2 of "code for design of primary and secondary schools (GB 50099-2011)" 5.2, combined with the number of students in each class, we can get the minimum classroom area: $67.5 \mathrm{~m} 2$ for primary school classrooms, $75 \mathrm{~m} 2$ for middle school classrooms, i.e. 1.5 $\mathrm{m} 2$ per student. According to the requirements of the specification, it can be seen that the column network of ordinary classroom is at least $7900 * 8400$ (primary school) and $7900 * 9300$ (middle school). The continuous enrichment and optimization of educational resources has brought about changes in teaching space, which makes the general classroom area and the per capita use area of students increase, and the comfort of teaching space is improved.

\subsection{Professional classroom}

Nowadays, the requirements for students' professional skills are constantly improving, and the types of professional classrooms are also increasing. Such as calligraphy classroom, piano room, woodworking, metalworking classroom, 3D printing classroom, vr virtual room, etc. Traditional professional classrooms mainly include labor skills, art, music, dance classroom, computer network classroom, multimedia classroom, science laboratory, etc. The new professional classroom can be designed according to the size of the traditional classroom or combined with the specific needs of the school.

According to the provisions of "code for design of primary and secondary schools (GB 50099-2011)" and "standards of educational technology and equipment for primary and secondary schools in Jiangsu Province", the usable area of traditional professional classrooms is required, while the area of different professional classrooms is also different. According to the number of students and the average requirement of students, the area of professional teaching rooms is mostly 96120110, In order to modularize the classroom units, we usually unify

* Corresponding author: 75525400@qq.com 
the classroom area of $96 \mathrm{~m} 2$ and $120 \mathrm{~m} 2$ in design. When the area requirement is met, the column network is usually set at $9600 * 10000$ and $9600 * 8400$.

\subsection{Teachers' Office}

The teacher's office here refers to the teacher's office and the school administrative office. Teachers' offices are mostly scattered around the teaching area, which is convenient to serve all kinds of classes, and the use area varies with different schools. The teacher's office can be divided into grade group office and teaching and research group office. The teacher's office of grade group is located near the ordinary classroom of each grade, and the office of each course teaching and research group is generally located near its professional classroom, which is combined with the special classroom. The teaching and research groups of other courses can be set up in the vicinity of administrative office or library. According to the regulations, the per capita use area of teachers should not be less than 5 square meters. The administrative office of a school generally refers to the office that undertakes the daily school affairs and the use of educational administration personnel, such as educational administration and administrative office, general affairs office, conference room, general warehouse, duty room, etc. Among them, the school administration office should be set up in the convenient transportation place because it undertakes the daily contact between teachers and students; the educational administration office undertakes the daily teaching affairs, which can be combined with the teacher's office or set in a relatively close position; the general affairs office is responsible for logistics tasks, and its setting can be combined with warehouse, maintenance room, canteen, etc., and warehouse and other rooms are the users It is often set at the school gate, so the general affairs office and other rooms can also be set up at the entrance and exit of the school; the on duty room is generally used for school teachers and administrative staff, which can be used as supporting facilities for teaching teachers' office and administrative office.

\subsection{Toilet}

As an essential living and service room, toilet should be set in each floor of the teaching building. If conditions permit, toilet for male and female students and toilet for male and female teachers should be set. Men's and women's toilets can also be set up on the partition according to the actual conditions. The convenience of the toilet should be ensured while the sanitary environment quality of the whole teaching area should not be affected. The toilet should be provided with ventilation conditions or installed with ventilation exhaust and sewage pipes.

\section{The combination mode of unit space}

The above four types of units are distributed in the teaching area of the campus, providing teaching conditions for the students of the whole school. Students and teachers can carry out corresponding teaching and learning activities. Due to the requirements and regulations of our country's specifications for the design of classroom windows, as well as the limited requirements for the coordination of various functions, various unit spaces are combined in different modes.

\subsection{The combination of ordinary classroom and professional classroom}

According to the previous chapter, we can see that different classrooms have different use areas and functions. There are several ways to arrange classrooms with different areas and functions:

\subsubsection{Block layout}

It is a common mode that ordinary classrooms and professional classrooms are set up separately. In this way, it is not only convenient for the general classroom teaching building and the professional classroom teaching building to be separated from each other, but also to have a certain connection with each other. At the same time, the column network can also be set up in groups. But the first requirement of such a layout is that the land area is abundant, which is not suitable for some campus with limited land use. Moreover, this kind of layout increases the number of teachers' offices, which leads to unnecessary waste of space. At the same time, it may lead to long traffic flow between ordinary classrooms and professional classrooms, which is not convenient in actual use.

\subsubsection{Middle corridor layout}

In some campuses with limited land use, teaching buildings are often unable to design too many buildings because of the sunshine requirements and $25 \mathrm{~m}$ spacing requirements of teaching buildings. In the design, we often combine the ordinary classroom and the professional classroom in a teaching building. The common design method is the middle corridor layout, which is the ordinary classroom in the South and the professional classroom in the north. While ensuring the daylighting of ordinary classrooms, professional classrooms can also be arranged accordingly. The traffic flow line between the two is relatively short, and the two types of classrooms are more closely connected, and the use is more convenient and convenient. Ease the land shortage and other issues

The biggest advantage of this mode is to save land to the greatest extent, but there are also some disadvantages. The layout of middle corridor leads to poor lighting in the inner corridor, which will bring depression to the teaching space. The middle corridor layout also makes the plane layout too compact and provides less public space for users. In addition, some professional classrooms need to have good lighting and sunshine requirements, which can not be met in such layout mode, and need to be considered separately. Due to the different size requirements of professional classrooms and ordinary teachers, this kind of layout may bring difficulties in the layout of plane column network. 


\subsubsection{Zigzag layout}

In the current campus design, there are many teaching buildings will adopt the back shape layout. Generally speaking, the number of ordinary classrooms is far more than that of professional classrooms. Therefore, in the design, the general classrooms will be set in the south of the Huixing teaching building, and the professional classrooms will be arranged in the east-west direction. The corridor will be widened, which can not only increase the public activity space of the teaching building, but also optimize the layout of the classroom space and reduce the cost of land use. However, with the increasing attention of the whole society to education, the comprehensive development of students is required, more professional courses are opened, and the quality and quantity requirements of professional classrooms are also higher and higher. This layout may not meet the increasing requirements of the number of professional classrooms.

\subsubsection{Vertical layout}

Ordinary classroom and professional classroom are set in the same teaching building, hierarchical and partition setting is also a common method. It should be noted that in this mode, due to the different area required by different classrooms, the occupied column span is not uniform, which will lead to some difficulties in facade design.

In order to avoid such problems, we can put the professional classroom on the low floor, and the ordinary classroom on the second floor and above. The professional classroom still adopts a column span as a class, but the depth can be appropriately increased to meet the use needs. In addition, many professional classrooms for landing projects do not meet the requirements for classrooms in the specification, so they are often considered as multifunctional rooms to avoid many restrictions on facade and window opening in the design.

\subsubsection{Focus on the choice of combination form}

Each of the above-mentioned space combination forms has its advantages and disadvantages, which requires the designer to select the appropriate space combination form according to the actual land use scale and use requirements, and in some specific cases, these space layout forms can also be combined. When choosing the space combination form, it is necessary to meet the teaching requirements to the greatest extent, with students as the first consideration object.

\subsection{Combination of teachers' offices}

There are not too many restrictions on the combination of classroom and teacher's office. The teacher's office is set up as a supporting room for teachers. In the existing design concept, the priority of the teacher's office is lower than that of the classroom, so the teacher's office will be set up in some locations with relatively weak sunshine conditions in the teaching building, or the teacher's office will be set in the location with weak East-West lighting.
Of course, the setting of the teacher's office should also be designed according to the school's teaching mode. In the actual case, part of the school's teaching mode serves two classes for one teacher's office, so the teacher's office is located between the ordinary classrooms and is arranged at intervals; or the teacher's office is located at the end of the corridor, which is convenient for teachers to directly observe the students' going on and off class.

\section{Detail design of unit space}

\subsection{Interior design}

The interior of the classroom unit includes the platform, seats, student cabinets, lockers, etc., among which the podium and seats are common furniture in the classroom design. When setting these two kinds of furniture, attention should be paid to the relationship between the platform and the seats in the classroom, so as to ensure that each student can see the platform. Student cabinets are often designed together with classroom units, as shown in figure 1 . In the design, attention should be paid to the relationship between the height of cabinets and the height of students. Generally speaking, the scale of three-tier cabinets is more appropriate.

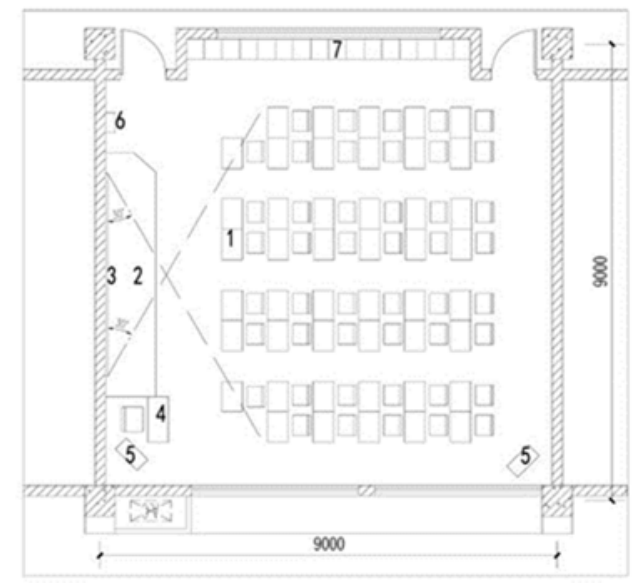

Fig. 1. enlarged picture of classroom

1. Desk (800mm in height) 2. Podium (height: $200 \mathrm{~mm}) 3$ finished blackboard $(900 \mathrm{~mm}$ from the bottom edge to the platform, 2200mm in height) 4. Seats for teachers; 5 . Cabinet type air conditioner; 6 . Broadcasting stereo; 7 . Storage cabinet $(400 \times 350 \mathrm{~mm})$

In addition, the wall skirt of the classroom unit should also be consistent with the interior design. The main function of wainscot is to protect the wall, and the height is usually $900-1100 \mathrm{~mm}$. In the design, we should consider the color and height, not only to meet the functional requirements, but also to make the teaching building corridor have a good visual effect.

\subsection{Window design of facade}

There are many technical regulations restricting the opening of windows on the exterior facade of classroom units. Among them, article 5.1.8 in the specification has an impact on the facade: the length of the end wall of the front side window of each classroom should not be less than 
$1.00 \mathrm{~m}$. The width of the wall between windows shall not be greater than $1.20 \mathrm{~m}$. In the design, this article mainly affects the distribution of ordinary classrooms and professional classrooms in different floors of the same teaching building. In the design, it is necessary to pay attention to this kind of classroom in advance and deal with it on the facade, such as controlling the window wall between windows, avoiding the end wall of $1 \mathrm{~m}$ classroom window in staggered floor design.

\subsection{Air conditioning design}

Air conditioning design is a problem that needs to be considered in every classroom. Generally, there are two treatment modes: one is to use the window end wall and the window wall to design and hide the external air conditioner. However, due to the size of the external air conditioner often needs to be larger than $1300 \mathrm{~mm}$, it needs to be considered uniformly; the other is to design the position of the windowsill under the window, which has the advantage of having enough length to hide the external unit, but because it is in the classroom To prevent the appearance of bay window, it is necessary to retract the window. It should be noted that different regions have different calculation methods for sunshine. Therefore, when using this method, whether there is self shielding should be considered and adjusted in combination with local regulations.

\section{Summary}

Education has always been an important social issue. In the construction industry, the discussion and thinking of educational buildings have never stopped. In recent years, China's attention to education has been increasing. As the main facilities for educational activities, schools are an important part of the education system. With the improvement of social concern, the responsibility of the school is increasing, and the requirements for school space are also higher and higher. Therefore, in the campus design, we should constantly adjust the thinking, explore and optimize the design of teaching unit space under the premise of meeting the norms, and create a relatively rich teaching space from the perspective of the educatee, so as to adapt to the social development Exhibition needs.

This paper analyzes and discusses the use area, layout mode and detail design of unit space in the teaching area. Based on the existing school space design, this paper analyzes its advantages and disadvantages, and puts forward a set of educational facilities space optimization design concept, which has certain design features and is easy to achieve from the perspective of the educated. Most of the optimal design schemes are combined with the engineering application.

\section{References}

1. Code for design of primary and secondary schools (GB 50099-2011). Beijing: China Construction Industry Press,( 2010-12)
2. Standard of educational technology and equipment for primary and secondary schools in Jiangsu Province (12th Five Year Plan). Department of education of Jiangsu Province.( July 2011)

3. Qian Xiaofei. Designing educational space: the formation of American modern school architectural concept . Comparative education research, (2020,42 (11): 45-52)

4. Shao Lu. Reflection on teaching reform of "office space design" course in Colleges and universities. Road to success, ( 2020 (28): 20-21)

5. Che Zhiyuan, Osama. Space design of teaching buildings in Xiamen primary and secondary schools under the new concept of Education [J]. Urban architecture, (2020,17 (22): 151-153)

6. Xia Bing. Review and Prospect of innovative campus space planning and design $[\mathrm{J}]$. Urban architecture, (2020,17 (16): 70-72)

7. Tian Yuan, Jia Xiaohu. Thinking on the design strategy of high plot ratio primary and secondary schools [J]. Architecture and culture, 2020 (03): 181182 